\title{
Evaluation of MMP2, Caspase-3 and C-Kit Expression on Thyroid Papillary Cancer Prognosis
}

\author{
Arzu Boztaş ${ }^{1}$, Hakan Buluş², Gülçin Güler Şimşek³, Altan Aydın ${ }^{4}$ Arzu Kaya Koçdoğan ${ }^{5}$, Volkan \\ Ateş $^{6}$, Serpil Oğuztüzün ${ }^{* 7}$ \\ ${ }^{1}$ Karabük Training and Research Hospital Department of General Surgery, Karabük, Turkey. \\ orcid.org/0000-0002-4702-8559 \\ 2 University of Health Sciences, Keçiören Training and Research Hospital Department of General Surgery, \\ Ankara, Turkey. orcid.org/0000-0001-7439-8099 \\ 3 University of Health Sciences, Gülhane Hospital, Department of Pathology, Ankara, Turkey. \\ orcid.org/0000-0001-7710-4631 \\ ${ }^{4}$ Trabzon of Public Hospital Department of General Surgery, Trabzon, Turkey. \\ orcid.org/0000-0002-2981-2833 \\ ${ }^{5}$ Istanbul Gelişim University, Vocational School of Health Services, Department of Patology Laboratory \\ Techniques, Istanbul, Turkey. orcid.org/0000-0002-3689-3061 \\ ${ }^{6}$ Kırıkkale University, Department of Informatics, Kırıkkale, Turkey. orcid.org/0000-0002-2349-0140 \\ ${ }^{7}$ Kırıkkale University, Faculty of Arts and Sciences, Department of Biology, Kırıkale, Turkey. \\ orcid.org/0000-0002-5892-3735 \\ *Corresponding author: soguztuzun@yahoo.com
}

Received: 14 April 2021, Accept: 04 May 2021, Published Online: 01 June 2021

\begin{abstract}
A number of new molecular and genetic factors are currently being studied in determining the prognosis of thyroid papillary carcinoma. In our study, we aimed to determine if there was a relationship between prognostic factors and expression of Matrixmatalloproteniase 2 (MMP-2), the tyrosine-kinase receptor CD117 (c-kit) and caspase-3. MMP2, c-kit and caspase-3 by immunohistochemical $(\mathrm{IHC})$ method were studied in both intact and pathological tissue of the thyroid gland removed after surgery in patients with thyroid papillary cancer. Prognostic factors such as age, histological stage, extrathyroidal spread, metastasis, tumor size were also evaluated. There was no statistically significant difference between prognosis and c-kit, MMP-2 and caspase-3 expression in patients $(p>0.05)$. Clinicopathological parameters were thought to be more important than $c-k i t$, caspase 3 and MMP2 in predicting prognosis in thyroid papillary cancers.
\end{abstract}

Key words: Thyroid papillary carcinoma, MMP-2, C-kit, Caspase-3 


\section{Introduction}

Thyroid malignant tumors account for less than $1 \%$ of all malignant tumors. Papillary thyroid cancers are the most common thyroid cancer and about $80 \%$ of all thyroid cancers. lodine deficiency and radiation play important roles in etiology of thyroid cancer, but genetic factors play a role in up to $5-10 \%$. Its prognosis is fairly good and the10-years survival rate is over $95 \%$. Today, many new molecular and genetic factors are being investigated in determining its prognosis. In many studies, it has been suggested that the expression of MMP2 is high in tumor tissue and plays a role in extracellular matrix and basal membrane destruction, thus increasing tumor aggression (Saffar et al., 2003). It is thought that the decreased of c-kit and caspase-3 expression will cause malignant transformation of thyroid tissue (Mishunina et al., 2010; Aydın et al., 2006).

In our study, we aimed to determine whether there is a relationship between MMP2, c-kit, caspase-3 expressions that contribute to malignant transformation and prognostic factors such as tumor size and age, histological stage, extrathyroidal spread, metastasis in papillary thyroid cancer.

\section{Material and Methods}

Between 2009 and 2015, 60 patients (Female/Male: 52/8) who underwent surgery due to thyroid papillary cancer at Ankara Keçiören-Educational Research Hospital General Surgery Clinic were included in the study. The study was approved by the Ethics Committee of Ankara Keçiören-Educational Research Hospital and informed consent was obtained from the patients. Preoperative USG (ultrasonography), age, sex, TFT (thyroid function test) level, postoperative pathology results, tumor size, lymph node involvement, capsule and vascular invasion were collected. These data were then transferred to patient follow-up forms. The special sections removed after thyroidectomy were reviewed and the best samples of the tumor were selected. Immunohistochemical evaluation was performed using appropriate kits. The preparations to be taken to the study were evaluated by the same pathologist in the pathology laboratory of our hospital. Expression of MMP2, caspase-3 and c-kit in thyroid tumor tissue was evaluated immunohistochemically and it was determined whether the patients had any association with tumor aggressiveness such as lymph node involvement, capsule and vascular invasion.

The tissue sections taken to poly-L-lysine coated slides were stained in CD117/c-kit (Biocare Medical PME296AA) 1:50, MMP2 (GeneTex GTX14577) 1:200, caspase-3 (GeneTex GTX73090) 1:1000 antibody dilutions by immunohistochemistry (IHC) method after deparafinization according to the reference (Koyun et al., 2020).

Brown colour in cytoplasm and/or nucleus of epithelial cells of the thyroid tissue was evaluated as positive staining. Scoring was also performed by pathologists unaware of the patients' clinical information. For the intensity of the reaction-negative $(-)$, weak $(1+)$, moderate $(2+)$ or strong $(3+)$-was determined in order to describe the immunoreactions.

In the study and control group tissues, the differences between protein expressions were searched by Pearson correlation test with $95 \%$ accuracy, to investigate the relations between clinical data, such as MannWhitney U-test; MMP-2, caspase-3 and c-kit expressions of patients' papillary thyroid cancer tissues and their prognostic factors. 


\section{Results and Discussion}

Sixty patients with thyroid papillary cancer were examined in this study. The mean age of the patients studied was $47.37 \pm 16.23(22-80)$ years and $26 \%(n=43.3)$ were younger than 45 years, while $86.7 \%(n=52)$ were female, $13.3 \%(n=8)$ were male, and the ratio of female to male was $6.5: 1$ (see details in Table 1). The histopathological features of the malignancies of the patients are explained in Table 2.

Table 1. Demographic characteristics of patients.

\begin{tabular}{|l|l|c|}
\hline$(\mathrm{n}=60)$ & & $\bar{X} \pm$ S (min-max) / number (\%) \\
\hline \multirow{3}{*}{ Age (year) } & & $47.37 \pm 16.23(22-80)$ \\
\cline { 2 - 3 } & $<45$ age & $26 /(43.3)$ \\
\cline { 2 - 3 } & $\geq 45$ age & $34 /(56.7)$ \\
\hline \multirow{2}{*}{ Gender } & male & $8 /(13.3)$ \\
\cline { 2 - 3 } & female & $52 /(86.7)$ \\
\hline \multirow{X}{X}{$:$ average; S: Standart deviation; \%: percentage } \\
\hline
\end{tabular}

Table 2. Histopathological features of patient malignancies.

\begin{tabular}{|c|c|c|c|}
\hline \multicolumn{2}{|l|}{$(n=60)$} & \multirow{2}{*}{\multicolumn{2}{|c|}{$\frac{\bar{X} \pm S(\min -\max ) / \text { number (\%) }}{29 /(48.3)}$}} \\
\hline \multirow{5}{*}{ Diagnosis } & Classic type & & \\
\hline & Micropapillary type & \multicolumn{2}{|c|}{$24 /(40.0)$} \\
\hline & Oncocytic variant & \multicolumn{2}{|c|}{$3 /(5.0)$} \\
\hline & Follicular variant & \multicolumn{2}{|c|}{$3 /(5.0)$} \\
\hline & Diffuse sclerosing variant & \multicolumn{2}{|c|}{$1 /(1.7)$} \\
\hline \multirow{3}{*}{ Tumor stage } & Stage-I & \multicolumn{2}{|c|}{$51 /(85.0)$} \\
\hline & Stage-II & \multicolumn{2}{|c|}{$3 /(5.0)$} \\
\hline & Stage-III & \multicolumn{2}{|c|}{$6 /(10.0)$} \\
\hline Tumor Diameter $(\mathrm{cm})$ & \multicolumn{3}{|c|}{$1.32 \pm 0.96(0.2-4.5)$} \\
\hline & Capsule Invasion & Vascular Invasion & LAP \\
\hline No & $53(88.3)$ & $54(90.0)$ & $46(76.7)$ \\
\hline Yes & $7(11.7)$ & $6(10.0)$ & $14(23.3)$ \\
\hline
\end{tabular}

C-kit was detected in normal thyroid tissue in $3.3 \%$ of patients $(n=2)$, while MMP-2 and caspase- 3 were not detected in normal thyroid tissue (see details in Table 3). According to the evaluation of malignant thyroid tissues, c-kit was found in 15.0\% ( $n=9)$, MMP-2 in 21.7\% ( $n=13)$ and caspase-3 in 21.7\% ( $n=13)$ (Table 3).

Table 3. Presence of c-kit, MMP-2 and caspase-3 in normal and malignant tissues.

\begin{tabular}{|l|c|c|}
\hline$(\mathrm{n}=60)$ & \multicolumn{2}{|c|}{ Number (\%) } \\
\hline & Normal Tissue & Malign Tissue \\
\hline c-kit & $2(3.3)$ & $9(15.0)$ \\
\hline MMP-2 & 0 & $13(21.7)$ \\
\hline Caspase-3 & 0 & $13(21.7)$ \\
\hline$\%$ : Percentage \\
\hline
\end{tabular}

There was no statistically significant difference in the presence of c-kit, MMP-2 and caspase-3 between age groups, sex, tumor stage groups, capsule invasion status, vascular invasion status and LAP (lymphadenopathy) ( $p>0,05)$ (Table 4). 
Tablo 4. Accordingly, age, gender, tumor stage, capsular invasion, vascular invasion and lymphadenopathy; presence of c-kit, mmp-2 and caspase-3 in thyroid malignant tissue.

\begin{tabular}{|c|c|c|c|c|}
\hline \multirow{2}{*}{\multicolumn{2}{|c|}{$(n=60)$}} & c-kit & MMP-2 & Caspase-3 \\
\hline & & \multicolumn{3}{|c|}{ Number $\left(\%^{*}\right)$} \\
\hline \multirow{3}{*}{ Age (year) } & $<45$ & $3(11.5)$ & $6(23.1)$ & $6(23.1)$ \\
\hline & $\geq 45$ & $6(17.6)$ & $7(20.6)$ & $7(20.6)$ \\
\hline & $p$ & $0.719 a$ & 0.817 & 0.817 \\
\hline \multirow{3}{*}{ Gender } & Male & 0 & $1(12.5)$ & $1(12.5)$ \\
\hline & Female & $9(17.3)$ & $12(23.1)$ & $12(23.1)$ \\
\hline & $p$ & $0.339^{a}$ & $0.673^{a}$ & $0.673^{a}$ \\
\hline \multirow{3}{*}{ Tumor stage } & Early stage (I-II) & $7(13.0)$ & $11(20.4)$ & $11(20.4)$ \\
\hline & Advanced stage (III) & $2(33.3)$ & $2(33.3)$ & $2(33.3)$ \\
\hline & $p$ & $0.218^{a}$ & $0.602^{a}$ & $0.602^{\mathrm{a}}$ \\
\hline \multirow{3}{*}{$\begin{array}{l}\text { Capsule } \\
\text { Invasion }\end{array}$} & No & $7(13.2)$ & $11(20.8)$ & $12(22.6)$ \\
\hline & Yes & $2(28.6)$ & $2(28.6)$ & $1(14.3)$ \\
\hline & $p$ & $0.281^{a}$ & $0.639^{a}$ & $0.998^{a}$ \\
\hline \multirow{3}{*}{$\begin{array}{l}\text { Vascular } \\
\text { Invasion }\end{array}$} & No & $7(13.0)$ & $11(20.4)$ & $13(24.1)$ \\
\hline & Yes & $2(33.3)$ & $2(33.3)$ & 0 \\
\hline & $p$ & $0.218^{a}$ & $0.602^{a}$ & $0.324^{a}$ \\
\hline \multirow{3}{*}{ LAP presence } & No & $6(13.0)$ & $9(19.6)$ & $8(17.4)$ \\
\hline & Yes & $3(21.4)$ & $4(28.6)$ & $5(35.7)$ \\
\hline & $p$ & $0.423^{a}$ & $0.478^{a}$ & $0.159^{a}$ \\
\hline
\end{tabular}

Table 5. Range of tumor diameter according to presence of c-kit. MMP-2 and caspase-3 in malignant tissue.

\begin{tabular}{|c|c|c|c|c|}
\hline \multirow{2}{*}{\multicolumn{2}{|c|}{$(n=60)$}} & \multirow{2}{*}{$n$} & Tumor diameter $(\mathrm{cm})$ & \multirow{2}{*}{$p$} \\
\hline & & & $\bar{X} \pm S$ (min-maks) & \\
\hline \multirow{2}{*}{ c-kit } & No & 51 & $1.27 \pm 0.92(0.2-4.0)$ & \multirow{2}{*}{0.335} \\
\hline & Yes & 9 & $1.58 \pm 1.22(0.2-4.5)$ & \\
\hline \multirow{2}{*}{ MMP-2 } & No & 47 & $1.42 \pm 1.05(0.2-4.5)$ & \multirow{2}{*}{0.281} \\
\hline & Yes & 13 & $0.95 \pm 0.38(0.3-1.7)$ & \\
\hline \multirow{2}{*}{ Caspase-3 } & No & 47 & $1.41 \pm 1.02(0.2-4.5)$ & \multirow{2}{*}{0.192} \\
\hline & Yes & 13 & $0.98 \pm 0.62(0.2-2.5)$ & \\
\hline
\end{tabular}

There was no statistically significant difference in the tumor diameter between c-kit, MMP-2 and caspase3 in the patients included in the study $(p>0.05)$ (Table 5). 
Table 6. Prognostic range; According to presence of c-kit, MMP-2 and caspase-3.

\begin{tabular}{|c|c|c|c|c|}
\hline & \multicolumn{2}{|c|}{ Prognosis situations } & \multirow{3}{*}{$p$} \\
\hline & & Good $(n=21)$ & $\operatorname{Bad}(n=39)$ & \\
\hline & & \multicolumn{2}{|c|}{ Number $\left(\%{ }^{*}\right)$} & \\
\hline \multirow{2}{*}{ c-kit } & No & $19(37.3)$ & $32(62.7)$ & \multirow{2}{*}{$0.473^{\mathrm{a}}$} \\
\hline & Yes & $2(22.2)$ & $7(77.8)$ & \\
\hline \multirow{2}{*}{ MMP-2 } & No & $16(34.0)$ & $31(66.0)$ & \multirow{2}{*}{0.767} \\
\hline & Yes & $5(38.5)$ & $8(61.5)$ & \\
\hline \multirow{2}{*}{ Caspase-3 } & No & $15(31.9)$ & $32(68.1)$ & \multirow{2}{*}{$0.349^{a}$} \\
\hline & Yes & $6(46.2)$ & $7(53.8)$ & \\
\hline
\end{tabular}

*Line percentage; aFisher's certain test

Of the patients included in the study, those aged 45 and over, those with advanced stage tumors, those with capsule and vascular invasion, and those with LAP were assessed as having a poor prognosis. According to this, 39 patients with any of the above were considered to have a poor prognosis. There was no statistically significant difference between prognosis of patients with c-kit, MMP-2 and caspase-3 ( $p>0.05$ ) (Table 6).

No statistically significant differences were found in the presence of c-Kit, MMP-2 and caspase-3 among patients with and without normal TSH, sT3 and sT4 values. (p>0,05) (Table 7), (Figure 1).

Table 7. Range of presence of c-kit caspase-3 and MMP-2 patients who have normal and non-normal thyroid function tests.

\begin{tabular}{|c|c|c|c|c|}
\hline \multirow{2}{*}{\multicolumn{2}{|c|}{$(n=60)$}} & c-kit & MMP-2 & Caspase-3 \\
\hline & & \multicolumn{3}{|c|}{ number $\left(\%^{*}\right)$} \\
\hline \multirow{3}{*}{ TSH } & Normal & $8(16.0)$ & $10(20.0)$ & $12(24.0)$ \\
\hline & Non-Normal & $1(10.0)$ & $3(30.0)$ & $1(10.0)$ \\
\hline & $p$ & $0.998^{a}$ & $0.675^{a}$ & $0.436^{a}$ \\
\hline \multirow{3}{*}{ sT3 } & Normal & $2(15.4)$ & $2(15.4)$ & $1(7.7)$ \\
\hline & Low & $7(14.9)$ & $11(23.4)$ & $12(25.5)$ \\
\hline & $p$ & $0.998^{a}$ & $0.713^{a}$ & $0.262^{a}$ \\
\hline \multirow{3}{*}{ sT4 } & Normal & $6(17.1)$ & $8(22.9)$ & $6(17.1)$ \\
\hline & Non-Normal & $3(12.0)$ & $5(20.0)$ & $7(28.0)$ \\
\hline & $p$ & $0.722^{\mathrm{a}}$ & 0.791 & 0.314 \\
\hline
\end{tabular}



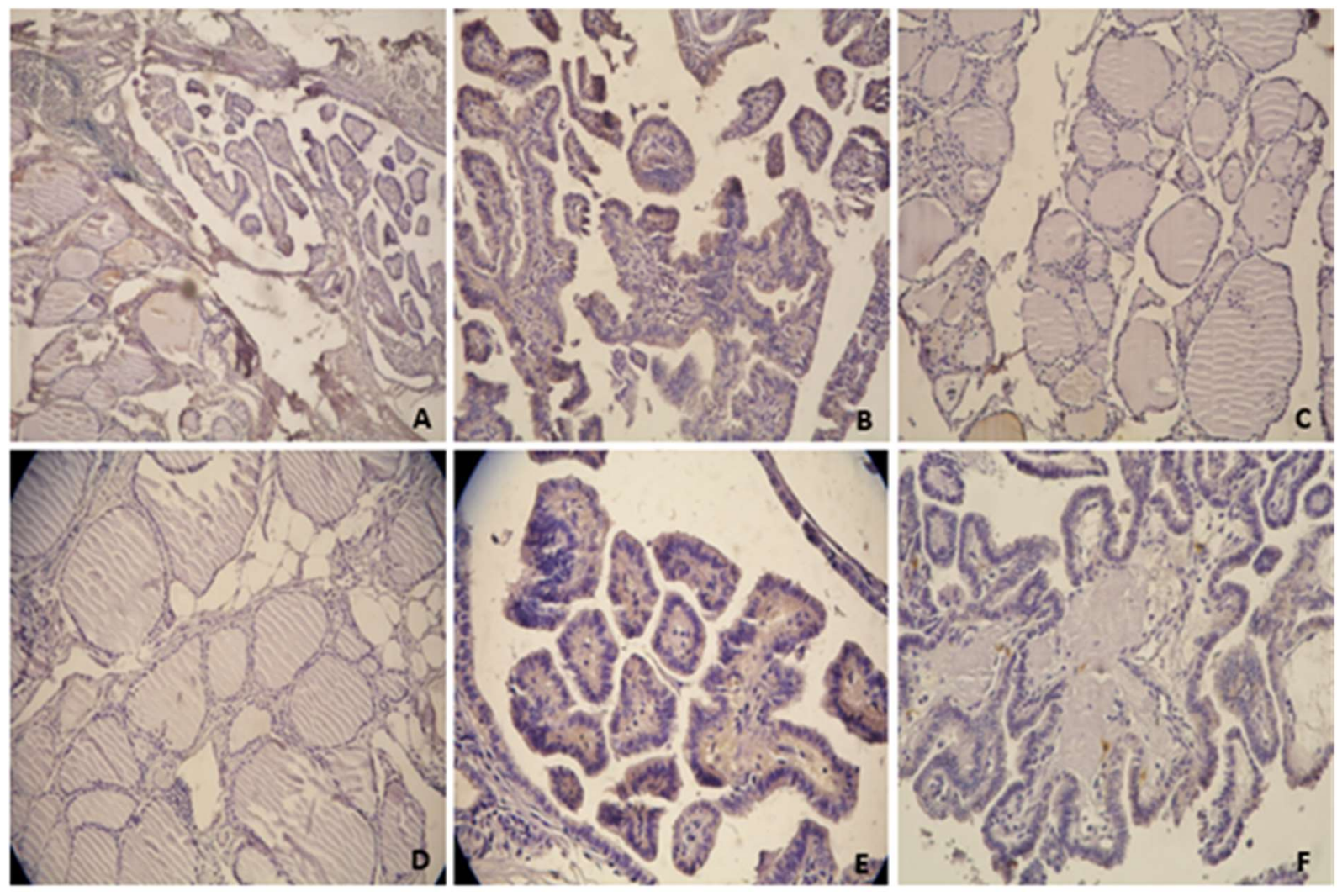

Figure 1. Immunohistochemical expressions of MMP2, caspase-3 and c-kit in thyroid papillary cancer and normal thyroid tissue.
A: Negative expression of MMP2 in Normal Thyroid Tissue
B: Positive expression of MMP2 in Thyroid Papillary Cancer Tissue
C: Negative expression of c-kit in Normal Thyroid Tissue
D: Positive expression of Caspase-3 in Normal Thyroid Tissue
E: Positive expression of Caspase-3 in Thyroid Papillary Cancer Tissue
F: Positive expression of c-kit in Thyroid Papillary Cancer Tissue

Cancer begins with uncontrolled division of cells by the effect of environmental factors. Only uncontrolled proliferation of cells is not enough to cancer emergence. Tumor needs to gain other malignant features like invasion and metastasis (Aliustaoğlu et al., 2009).

The extracellular matrix acts as a barrier for the growth and spread of tumor tissue. Extracellular matrix degradation is required for tumor cell invasion and spread in primary lesion or metastatic areas. Cancer cells use matrix metalloproteinases to break down this barrier (Apakkan et al., 2001; Hewitt et al., 1996; Matrisian et al., 1990; Sethi et al., 2000).

The MMP family consists of zinc-dependent proteins that resemble each other, which break down extracellular matrix and the basement membrane components. More than approximately $20 \mathrm{MMP}$ types have been identified in last 40 years and the role of MMPs in cancer development is still under study. These enzymes have become targets for cancer research because of their involvement in the cancer formation process via metastasis, invasion, angiogenesis, apoptosis inhibition and antitumor defense mechanisms (Kessenbrock et al., 2010; Amelina et al., 2010). MMP2, also known as gelatinase $A$, is one of the most important members of this family. Gelatinase 
A has been shown in both the stromal cells (endothelial cells, macrophages and fibroblasts) surrounding tumor aggregates as well as the mRNAs of tumoral epithelial cells. In some studies, it has been proven that MMP2 breaks down type 4 collagen in the basal membrane (Cvejic et al., 2000; Tryggvason et al., 1993). Nowadays some studies suggest that MMP2 plays a key role in the progressive progression of papillary thyroid cancer.

Study conducted by Tan et al. (2008) there was a significant correlation between MMP2 expression and extra-thyroid invasion and lymph node metastasis. However, they could not detect the relationship between tumor size and MMP2. The study conducted by Maeta et al. have not found a significant association between high MMP2 expression and lymph node metastasis, distant metastasis, vascular and intra-thyroidal invasion. They also suggested that there was a direct correlation between MMP2 expression and tumor size in Maeta et al. study (2001). Also, some similar studies have suggested the same results. For example, studies done by Cho Mar et al. (2006) and Campo et al. (1992) also found an accurate ratio between tumor invasion and metastasis status and MMP expression. Tian et al. (2008) and Liang et al. (2010) suggested that MMP2 can be used as an indicator in detecting the metastatic behavior of thyroid papillary cancer. Contrary to all these studies, the study of Cvejic et al. found that MMP2 expression was not associated with any clinical and pathological parameters. Saffar et al. found a positive association between MMP2 expression and vascular invasion in their study which is conducted on 80 patients with tyroid papillary cancer. However, they could not find significant association between MMP 2 expression and extrathyroidal spread. The data obtained in this study suggested that MMP2 could be used as an indicator in evaluating the aggressive behavior of papillary cancer.

In our study, MMP2 expression was not detected in immunohistochemically evaluated normal thyroid tissues in excised thyroid specimens of 60 patients with thyroid papillary cancer. However, $21.7 \%$ of the patients malignant tissue were positive for MMP2. Being over 45 years of age, advanced stage tumors, positive capsule and vascular invasion and LAP invasion were accepted as poor prognostic criteria. 39 of 60 patients with thyroid papillary cancer included in the study were considered to have poor prognosis. 8 of these 39 patients were found to have MMP2 positive. No statistically significant difference was found between MMP2 precence and prognosis in patients ( $p=0.767$ ) (see details in Tablo 6). There was no statistically significant difference also in TSH, sT3 and sT4 levels and MMP2 expression levels of the patients evaluated in the study $(P>0.05)$ (see details in Table 7). Programmed cell death, or apoptosis, plays an important role in the pathogenesis of tumors (Mishunina et al., 2010). Survival of the tumor cell based on activation of antiapoptotic pathways or inactivation of proapoptotic stimulation. Recent studies have revealed that the apoptotic process is mediated by a family of proteolytic enzymes called caspases. To this day 14 caspases have been identified. Caspase- 3 is one of the most important members of this family. Also some studies suggest that secretion of the caspase inhibitor by malignant cells stops apoptosis. Furthermore, autoimmune diseases and cancers are emerging as a results of defects in the caspases

Saffar et al conducted on papillary thyroid cancer patients found no significant difference was found between caspase- 3 expression and tumor aggressiveness $(p=0.647)$. Similar results were also found in the study of Zhang et al. (2009). In both studies, there was no significant difference found between caspase-3 expression in cancerous thyroid tissue and vascular invasion, capsule invasion, necrosis, lymph node involvement and metastasis. On the other hand, Mishunina et al. (2010) suggested that there is a relationship between lymph node 
involvement and metastasis and low expression of caspase-3. Likewise, Mader et al. (2003) suggested that caspase- 3 expression is associated with tumor size, metastasis, and poor prognosis.

In our study, there was no statistically significant difference between the patients' age, gender, tumor stage, capsule invasion, vascular invasion and presence of LAP and caspase-3 expression ( $p>0.05$ ). $46.2 \%$ of patients with caspase-3 positive were found to have good prognosis and $53.8 \%$ to poor prognosis, whereas $31.9 \%$ of those without caspase- 3 were found to have good prognosis and $68.9 \%$ had poor prognosis. There was no statistically significant difference found between patients with caspase-3 and prognosis $(p=0.349)$.

C-kit is a type 3 tyrosine kinase receptor and regulates apoptosis, cell differentiation, proliferation, chemotaxis and adhesion. It is normally found in skin epithelium, breast ductal epithelium and some neurons. According to some studies while c-kit was positive in normal thyroid tissue and benign lesions of thyroid, was not found in tissues with papillary thyroid cancer. Based on these studies it has been suggested that c-kit may be involved in control of the growth of the thyroid epithelium and c-kit deficiency may result in malignancy (Aydın et al., 2006; Natali et al., 1995).

There are very few studies in the literature regarding the evaluation of c-kit expression in thyroid papillary carcinomas. Natali et al. (1995) found in their 70 patient study that $60 \%$ of benign thyroid lesions were c-kit positive whereas $90 \%$ of papillary carcinoma lesions were c-kit negative. Tanaka et al. (1995) performed c-kit gene analysis using the northern blot method and came to the conclusion that decreased c-kit gene expression may be associated with malignant transformation. As a contrary to these studies, Aydın et al. (2006) found that more c-kit antibody was present in cancerous tissue than in normal tissue.

Similar to the results of Aydin et al. (2006) study, 2 of our patients with thyroid papillary carcinoma were found to have normal c-kit positive in normal thyroid tissue and 9 patients with cancer thyroid tissue were also found positive for c-kit. No statistically significant difference was found between the age, sex, tumor stage, capsule invasion, vascular invasion, LAP status and c-kit levels of the patients examined in the study. ( $p>0.05)$ In our study, $22.2 \%$ of patients with c-kit had good prognosis, $77.8 \%$ had poor prognosis; of the patients without c-kit, $37.3 \%$ had good prognosis and $62.7 \%$ had poor prognosis. No statistically significant difference was found between c-kit positivity and prognosis in patients $(\mathrm{p}=0.473)$.

\section{Conclusion}

Our data indicate that there was no statistically significant difference found between c-kit, MMP-2 and caspase expression and prognosis. Clinic and pathologic parameters (age, sex, tumor diameter, vascular invasion, extracapsular spread, lymph node involvement, distant metastasis status, and tumor stage) were found to be more important than immunohistochemical parameters in predicting prognosis in thyroid papillary carcinomas. Nevertheless, we believe that molecular and genetic markers should be investigated with large populations and long-term patient series.

\section{Conflicts of Interests}

Authors declare that there is no conflict of interests 


\section{References}

Aliustaoğlu, M. (2009). Temel kanser fizyopatolojisi. Klinik Gelişim, 22(3), 46-49.

Amelina, C., Caruntu, I. D., Gıuşca, S. E., \& Balan, R. A. (2010). Matrix metalloproteinases involvement in pathologic conditions. Romanian Journal of Morphology and Embryology, 51(2), 215-228.

Apakkan Aksun, S., Bayındır, O., \& Özmen, D. (2001). Metalloproteinazlar, inhibitörleri ve ilişkili fizyolojik ve patolojik durumlar. Türkiye Klinikleri Tıp Bilimleri, 21, 332-342.

Aydın, O., Yıldız, L., Kefeli, M., Yüksel, C., Süllü, Y. (2006). Tiroid papiller karsinomlarda c-kit. Türk Patoloji Dergisi, 22(1), 17-20.

Campo, E., Maria, J., Merino, J., Liotta, L., Neumann, R., \& Stetler-Stevenson, W. G. (1992). Distribution of the 72-kDa type IV collagenase in non-neoplastic and neoplastic thyroid tissue. Human Pathology, 23, 1395-1401.

Cho Mar, K., Eimoto, T., Tateyama, H., Arai, Y., Fujiyoshi Y., \& Hamaguchi, M. (2006). Expression of matrix metalloproteinases in benign and malignant follicular thyroid lesions. Histopathology, 48, $286-294$.

Cvejic, D., Savin, S., Paunovic, I., Tatic, S., \& Havelka, M. (2000) Immunohistochemical localization of matrix metalloproteinase-2(MMP-2) in medullary thyroid carcinoma. Archive of Oncology, 8, 95-97.

Franc, B. (2003). Observer variation of lesions of the thyroid. American Journal of Surgical Pathology, 27, 1177-1178.

Hewitt, R., \& Dan, K. (1996). Stromal cell expression of components of matrix degrading protease systems in human cancer. Enzyme Protein, 49,163-173.

Kessenbrock, K., Plaks, V., \& Werb, Z. (2010). Matrix Metalloproteinases: Regulators of the tumor microenvironment. Cell, 141(1), 52-67. https://doi.org/10.1016/j.cell.2010.03.015

Koyun, E., Karadag, R., Ozkanli, S., Oguztuzun, S., Kocdogan, A. K., \& Ozsoy, I. (2020) Caspase-3, p53 and $\mathrm{Bcl}-2$ expression in basal cell carcinoma of the eyelid. Advances in Dermatology and Allergology, 37(4), 535-539.

Liang, H., Zhong, Y., Luo, Z., Huang, Y., Lin, H., Luo, M., Zhan, S., Xie, K., Ma, Y., \& Li, Q. Q. (2010). Assessment of biomarkers for clinical diagnosis of papillary thyroid carcinoma with distant metastasis. International Journal of Biological Markers, 25, 38-45.

Maeta, H,, Ohgi, S., \& Terada, S. (2001). Protein expression of matrixmetalloproteinase 2 and 9 and tissue inhibitors of metalloproteinase 1 and 2 in papillary thyroidcarcinomas. Virchows Archiv, 438, 121-128.

Matrisian, L. M. (1990). Metalloproteinases and the inhibitors in matrixremodeling. Trends in Genetics, 6(4), 121-125.

Mishunina, T. M., Kalinichenko, O. V., Tronko, M. D., \& Statsenko, O. A. (2010). Caspase-3 activity in papillary thyroid carcinomas. Experimental Oncology, 32, 269-272.

Natali, P. G., Berlingieri, M. T., Nicotra, M. R., Santoro, E., Bigotti, A., \& Ullrich, A. (1995). Transformation of thyroid epithelium is associated with loss of c-kit receptor. Cancer Research, 55, 1787-1791. 
Saffar, H., Sanii, S., Emami, B., Heshmat, R., Panah, V. H , Azimi, S., \& Tavangar, S. M. (2003). Evaluation of MMP2 and Caspase-3 expression in 107 cases of papillary thyroid carcinoma and its association with prognostic factors. Pathology-Research and Practice, 209, 195-199.

Sethi, C. S., Bailey, T. A., Luthert, P. J., \& Chong, N. H. V. (2000) Matrix metalloproteinase biology applied to vitreo retinal disorders. British Journal of Ophthalmology, 84, 654-664.

Tan, H., Ye, K., Wang, Z., \& Tang, H. (2008). Clinicopathologic evaluation of immunohistochemical CD147 and MMP2 expression in differentiated thyroid carcinoma. Japanese Journal of Clinical Oncology, 338, 528-533.

Tanaka, T., Umeki, K, Yamamoto, I., Kotani, T., Sakamoto, F., Noguchi, S., \& Ohtaki, S. (1995). C-Kit protooncogene is more likely to lose expression in differentiated thyroid carcinoma than three thyroidspecificgenes: thyroid peroxidase, thyroglobulin, and thyroid stimulating hormone receptor. Endocrine Journal, 42, 723-728.

Tian, X., Cong, M., Zhou, W., Zhu, J., \& Liu, Q. (2008). Relationship between protein expression of VEGF-C, MMP-2 and lymph node metastasis in papillary thyroid cancer. Journal of International Medical Research, 36, 699-703.

Tryggvason, K., Hoyhtya, M., \& Ryke, C. (1993). Type IV collagenases in invasive tumors. Breast Cancer Research and Treatment, 24, 209-218.

Zhang, H. Y., Meng, X., Du, Z. X., Fang, C. Q., Liu, G. L., Wang, H. Q., \& Deng, W. W. (2009) Significance of survivin, caspase-3, and VEGF expression on thyroidcarcinoma. Clinical and Experimental Medicine, 9 , 207-213. 